\title{
Correction: Time-Dependent Impact of Irreversible Electroporation on Pancreas, Liver, Blood Vessels and Nerves: A Systematic Review of Experimental Studies
}

\author{
J. A. Vogel, E. van Veldhuisen, P. Agnass, J. Crezee, F. Dijk, J. Verheij, T. M. van Gulik, \\ M. R. Meijerink, L. G. Vroomen, K. P. van Lienden, M. G. Besselink
}

There are errors in the Results and Conclusions sections of the Abstract.

The last sentence of the Results section of the Abstract should read: In nerves, the median time until demonstrable histological changes was 24 hours.

The last sentence of the Conclusions section of the Abstract should read: Whereas pancreas and liver showed the first damages after 1-2 hours, this took 24 hours in nerves and 7 days in blood vessels.

\section{Reference}

1. Vogel JA, van Veldhuisen $E$, Agnass $P$, Crezee J, Dijk F, Verheij J, et al. (2016) Time-Dependent Impact of Irreversible Electroporation on Pancreas, Liver, Blood Vessels and Nerves: A Systematic Review of Experimental Studies. PLoS ONE 11(11): e0166987. doi:10.1371/journal.pone.0166987 PMID: 27870918

\section{f OPEn ACCESS}

Citation: Vogel JA, van Veldhuisen E, Agnass $P$, Crezee J, Dijk F, Verheij J, et al. (2017) Correction: Time-Dependent Impact of Irreversible Electroporation on Pancreas, Liver, Blood Vessels and Nerves: A Systematic Review of Experimental Studies. PLoS ONE 12(3): e0174018. doi:10.1371/ journal.pone.0174018

Published: March 10, 2017

Copyright: ๑ 2017 Vogel et al. This is an open access article distributed under the terms of the Creative Commons Attribution License, which permits unrestricted use, distribution, and reproduction in any medium, provided the original author and source are credited. 